UDC 616.33-002.27: 614.876: 519.235

DOI: $10.21668 /$ health.risk/2019.4.11.eng

\title{
RELATION BETWEEN ATROPHIC GASTRITIS AND RISK FACTORS PREVALENCE AMONG WORKERS EMPLOYED AT ATOMIC ENTERPRISE
}

\author{
E.I. Rabinovich, V.F. Obesnyuk, S.V. Povolotskaya, S.N. Sokolova, \\ M.A. Vasina, S.S. Sokol'nikova
}

The Southern Urals Biophysics Institute, 19 Ozerskoe drive, Ozersk, 456780, Russian Federation

Atrophy of the stomach mucosa in the stomach is a significant predisposing factor that causes elevated risks of stomach adenocarcinoma. It was shown that mortality caused by malignant neoplasms in the digestive organs accounted for $36 \%$ of all the death cases due to solid carcinoma among workers employed at basic enterprises included into "Mayak" Production Association (Mayak PA).

Our research goal was to study a relation between atrophic gastritis (AG) prevalence and potentially hazardous endogenous and exogenous factors among personnel employed at an atomic enterprise of Mayak PA.

We analyzed data obtained via clinical and laboratory examinations performed on a sampling that was made of 1,116 people, $70 \%$ of them being workers employed at Mayak PA.

Our research allowed us to reveal and analyze 26 hazardous factors that contributed to AG development. Data array was processed with a modified "case - control" procedure based on well-known principal components analysis. Observation clusters and strata that formed certain groups in various areas of the factor space differed both as per "overloading" with risk factors and as per intensity of an effect. Accomplished analysis allowed us to conclude that there was a correlation between $A G$ development and risk factors prevalence as we revealed certain factors exerting statistically significant impacts on $A G$ development in the examined sampling even within the zero hypotheses HO. In order to determine how intense that relation was, in further analysis it was advisable to apply an alternative hypothesis $H 1$ on a possible relation between an effect and examined factors. Application of a modified statistical procedure allowed us to make any conclusions only on certain trends occurring in AG risks when there were some changes in aggregated overloading with risk factors; adequate and complete statistical analysis can only be multi-factor one. As "factor-effects" relations lack evidence, it creates a possibility for artificial neural networks approximations; we are going to demonstrate it in our future works.

Key words: atomic enterprise, personnel, atrophic gastritis, clinical and laboratory examination, risk factors, principal component analysis, one-factor analysis, multi-factor analysis.

According to official statistic data stomach cancer (SC) holds the third rank place in the structure of mortality caused by malignant neoplasms $[1,2]$. Gastric mucosa (GM) atrophy is a significant predisposing factor that causes elevated risks of stomach adenocarcinoma. Given that, atrophic gastritis (AG) is the first section in "precancerous cascade" chain that results in stomach cancer [3-5]. Despite risk factors that cause stomach cancer and $A G$ being rather close [6], some of them that are proven to be related to SC don't cause GM atrophy. Thus, for example, an established negative influence exerted by sex and smoking on $\mathrm{SC}$ occurrence is quite disputable in case of $A G[7-9]$.

In this relation it seems truly vital to examine a correlation between AG and potentially hazardous endogenous and exogenous factors, especially concerning people who

(C) Rabinovich E.I., Obesnyuk V.F., Povolotskaya S.V., Sokolova S.N., Vasina M.A., Sokol'nikova S.S., 2019

Evgeniya I. Rabinovich - Candidate of Medical Sciences, Senior researcher, Head of the Radiation Biochemistry Laboratory (e-mail: lab8@subi.su, tel.: +7 (35130) 74-447; ORCID: https://orcid.org/0000-0002-1593-8881).

Valerii F. Obesnyuk - Candidate of Physical and Mathematical Sciences, Senior researcher at the Radiation Epidemiology Laboratory (e-mail: v-f-o@subi.su, tel.: +7 (35130) 74-447; ORCID: https://orcid.org/0000-0002-2446-4390).

Svetlana V. Povolotskaya - Candidate of Biological Sciences, Senior researcher at the Radiation Biochemistry Laboratory (e-mail: povolotskaja@subi.su, tel.: +7 (35130) 71-805; ORCID: https://orcid.org/0000-0002-0324-3257).

Svetlana N. Sokolova - Leading Programming Engineer (e-mail: sokolova s@subi.su, tel.:+7(35130) 75-670; ORCID: https: //orcid.org/0000-0001-5505-7950);

Mariya A. Vasina - Junior researcher at the Radiation Biochemistry Laboratory (e-mail: lab8@subi.su; tel.:+7 (35130) 71-805; ORCID: https://orcid.org/0000-0001-6784-6105);

Sof'ya S. Sokol'nikova - Junior researcher at the Radiation Biochemistry Laboratory (e-mail: lab8@subi.su, tel.: +7 (35130) 71-805; ORCID: https://orcid.org/0000-0003-4861-5568). 
were exposed to occupational external and internal irradiation and hazardous chemicals, in particular, workers employed at nuclear enterprises included into Mayak Production Association (Mayak PA). It was shown that solid tumors in the gastrointestinal tract held the $3-4^{\text {th }}$ rank places in the structure of mortality and morbidity caused by malignant neoplasms (MN) among workers employed at Mayak PA; mortality caused by $\mathrm{MN}$ in the digestive organs accounted for $36 \%$ among workers employed at major enterprises included into Mayak PA $[10,11]$. Previously we detected that AG prevalence among workers employed at Mayak PA was statistically significantly 3-4 times higher than among people who weren't exposed to occupational risk factors [12]. Our present work is an attempt to perform detailed analysis of correlations between a great number of risk factors and AG for a more representative sampling. When atrophic state of GM is revealed, it can allow spotting out people who run elevated risks of SC occurrence; it can also make managing individual risks more efficient and allow performing prevention activities in order to prolong a working period for a specific worker. It will also make for a decrease in overall specific parameters of mortality with $\mathrm{SC}$ in the population [13].

Data and methods. Our sampling was made up of 1,116 people and consisted of 614 workers employed at major enterprises included into Mayak PA, 181 workers employed at auxiliary enterprises in Mayak PA, and 320 people who worked in nonindustrial establishments. The structure of our sampling proved it was a heterogeneous one in terms of epidemiologic research. Demographic data and data on occupational and non-occupational risk factors $(F)$ that caused gastric diseases were obtained via questioning and case histories examination. All people included into the sampling underwent laboratory examinations to check functional state of the stomach with "serologic biopsy" ("Gastro Panel", Finland). We identified various phenotypes of GM state as per a combination of pepsinogen-1, gastrin-
17, and IgG antibodies to H. pylori in blood serum [14]. Normal stomach functioning was detected in 165 cases; non-atrophic Helicobacter pylori (H.pylori)-associated gastritis, in 814 cases; atrophic gastritis, in 137 cases.

To reveal any relation between $A G$ and risk factors prevalence, we applied a hybrid procedure which we modified ourselves; the procedure combined certain traits of "case control" study and group factor analysis based on principal components technique [15]. Our modification was primarily about "cases" and "controls" not being divided into pairs of traditional groups that either had or didn't have an examined risk factor; we divided them into several fixed strata that had different "burden" with all the factors with a relevant difference in a significance of an observed effect. This procedure can be considered as a certain substitute to multi-factor analysis applied to examine a relation between an effect and factors; this analysis, just as "case - control" analysis, is applied for groups with different effects; it allows analyzing a nature of distribution for each factor separately (a one-factor analysis). Within a zero hypothesis $(\mathrm{HO})$ which assumes there is no correlation between an effect and factors there should be no statistical difference in prevalence of factors or an effect between strata. On the contrary, statistical significance of discrepancies between factors, provided that there are differences in an effect, will allow not only revealing potentially hazardous factors but also ranking them and comparing a risk trend with a factor prevalence trend. In addition to that, group prevalence and intergroup relative $A G$ risks were estimated within Bayesian approach as per relevant betadistributions [16, 17].

Results and discussion. Table 1 contains factors $(F)$ that can exert their influence on $A G$ occurrence according to our own data and those taken from literature $[7-9,12,18]$. We can assume there is a statistical correlation between $A G$ and influencing factors as per results obtained via comparing distributions of all observations and specific events in the factors space. 
Table 1

Examined factors that influence AG occurrence and their distribution in the sampling

\begin{tabular}{|c|c|c|c|c|}
\hline No. & Factor & $\begin{array}{l}\text { Factor } \\
\text { value }\end{array}$ & $\begin{array}{l}\text { Number of } \\
\text { people with } \\
\text { factor value } \\
\text { "1" }\end{array}$ & $\begin{array}{l}\text { Per cent of } \\
\text { people with } \\
\text { factor value } \\
\text { "1" }\end{array}$ \\
\hline 1 & Age at the moment of screening (years) & $36-82$ & - & - \\
\hline 2 & Sex (female) & {$[0 ; 1]$} & 491 & $44 \%$ \\
\hline 3 & Alcohol intake & {$[0 ; 1]$} & 835 & $74.8 \%$ \\
\hline 4 & Smoking & {$[0 ; 1]$} & 350 & $31.4 \%$ \\
\hline 5 & $\begin{array}{l}\text { Exposure to radiation caused by living on territories } \\
\text { contaminated due to accidents at Mayak PA }\end{array}$ & {$[0 ; 1]$} & 260 & $23.3 \%$ \\
\hline 6 & $\begin{array}{l}\text { A dose of occupational } \gamma \text {-irradiation on the gastroin- } \\
\text { testinal tract (mGy) }\end{array}$ & $0-475$ & - & - \\
\hline 7 & $\mathrm{Pu}$ contents $(\mathrm{kBq})$ & $0-0,78$ & - & - \\
\hline 8 & Organic chemicals with carcinogenic effects & {$[0 ; 1]$} & 306 & $27.5 \%$ \\
\hline 9 & Organic chemicals with gastrotoxic effects & {$[0 ; 1]$} & 171 & $15.4 \%$ \\
\hline 10 & Generally toxic organic chemicals & {$[0 ; 1]$} & 371 & $33.3 \%$ \\
\hline 11 & Non-organic chemicals with carcinogenic effects & {$[0 ; 1]$} & 212 & $19.0 \%$ \\
\hline 12 & Non-organic chemicals with gastrotoxic effects & {$[0 ; 1]$} & 408 & $36.6 \%$ \\
\hline 13 & Generally toxic non-organic chemicals & {$[0 ; 1]$} & 295 & $26.5 \%$ \\
\hline 14 & Extragastric precancerous diseases & {$[0 ; 1]$} & 24 & $2.2 \%$ \\
\hline 15 & Extragastric MN & {$[0 ; 1]$} & 33 & $2.9 \%$ \\
\hline 16 & Extragastric hormone-dependent benign tumors (BT) & {$[0 ; 1]$} & 73 & $6.5 \%$ \\
\hline 17 & Extragastric hormone-independent BT & {$[0 ; 1]$} & 56 & $5.0 \%$ \\
\hline 18 & Autoimmune diseases (AID) & {$[0 ; 1]$} & 69 & $6.2 \%$ \\
\hline 19 & Type-II diabetes mellitus (DM) & {$[0 ; 1]$} & 89 & $8.0 \%$ \\
\hline 20 & Gastric acid-dependent diseases & {$[0 ; 1]$} & 261 & $23.4 \%$ \\
\hline 21 & Non-ulcer gastric diseases & {$[0 ; 1]$} & 223 & $20.0 \%$ \\
\hline 22 & Maternal SC predisposition & {$[0 ; 1]$} & 41 & $3.7 \%$ \\
\hline 23 & Paternal SC predisposition & {$[0 ; 1]$} & 80 & $7.2 \%$ \\
\hline 24 & Maternal gastric / duodenum ulcer predisposition & {$[0 ; 1]$} & 26 & $2.4 \%$ \\
\hline 25 & Paternal gastric / duodenum ulcer predisposition & {$[0 ; 1]$} & 87 & $7.8 \%$ \\
\hline 26 & Concentration of IgG antibodies to H.pylori (EIU) & $0.5-135.5$ & - & - \\
\hline
\end{tabular}

Note:

1. Factors No. 1,6,7,26 are quantitative; all the others are categorical;

2. Hormone-dependent BT (benign prostatic hyperplasia, uterine myoma), hormone-independent BT (all the rest, predominantly polyps);

3. Autoimmune diseases excluding diabetes mellitus.

It is geometrically impossible to show distribution of all 26 factors in a fully-dimensional space $\left(\mathrm{R}^{26}\right)$; so, to give a relevant illustration, we compared one-dimension empiric distributions in a projection of the main trend in factors changeability. This analysis technique can be seen as an analogue to the simplest variant of principal component analysis [15]. To do that, we performed centering and standardizing for each factor $\mathrm{F}$ as per standard deviation value thus making each factor acquire a standardized weight that was not higher than 1 as per its module. Therefore, each specific individual had certain conditional vector "burden" with factors (aggregated factor burden) within 26-dimension space. A shift along the first major direction turned out to be predominantly determined by a positive influence exerted on AG occurrence by an increase in age (F1) and hor- 
mone-dependent benign tumors (F16) as well as negative contribution made by ulcer in mother's case history (F24). The major trend in factors changeability was determined along a straight line that connected two extreme individuals with a maximum distance between state vectors with standardized coordinates; their initial characteristics are given below.

The first extreme individual had the following risk factors that could cause AG: age equal to $43(\mathrm{~F} 1)$; proneness to regular alcohol intake (F3); duodenum ulcer (F20); hereditary predisposition to ulcer (mother had it (F24); substantially increased concentration of antibodies to $H$. pylori, namely 91.4 EIU.

The second extreme individual had the following potential AG risk factors: age equal to 73 (F1); proneness to regular alcohol intake (F3); benign prostatic hyperplasia (F16); nonulcer gastric diseases (F21); concentration of antibodies to $H$. pylori amounted to $31.1 \mathrm{EIU}$ which was insignificantly higher than its threshold value (30 EIU). We should note that there was no AG in both cases.

Figure 1 shows graduated graphs for two empiric distributions of all cases and AG cases in the sampling that are characterized with the constant sign of a shift in one distribution relative to another. Within a zero hypothesis as per signs criterion such an event seems to be almost impossible and it indicates there is a nonrandom correlation between $\mathrm{AG}$ occurrence and at least several examined factors. Nevertheless, when two dispersions don't coincide, it shows there is a statistic correlation between an effect and factors.

Along with a graphic way applied to show that dispersions don't coincide, we also applied table stratification of events in onedimension space of the major trend (Table 2). We selected stratification conditions as per the single uninterrupted scale showing the aggregated factor burden so that discrepancies in AG prevalence between strata were as statistically significant as it was only possible. In this case discrepancies in an effect can be correlated to discrepancies in distribution of both specific factors and the aggregated one as per strata. To make interpretation more convenient, we assigned the aggregated coordinate 0 to the first extreme individual, and 9.77 (a length of difference between vectors), to the second extreme individual; therefore, all the cases along the major trend were distributed in the interval [0-9.77]. The section was conditionally divided into 4 strata according to the following intervals: S1 (0-4.8); S2 (4.8-6.2); S3 (6.2-8.1), and S4 (8.1-9.77).

Strata S1, S2, S3, and S4 can be described verbally notwithstanding the fact that they don't have well-defined boundaries in the space of the first principal component. Thus, S1, unlike S2, S3, and S4, contains cases with the least average age, the least average $\gamma$-irradiation doses and radionuclides contents; there were no people with pancreatic diabetes, pre-cancer diseases and MN not located in the stomach in this stratum. But still, prevalence of gastric acid-dependent diseases was rather high among participants in this stratum; smoking was the most widely spread in this stratum; it had the highest average concentration of antibodies to H.pylori; and all 26 registered cases of ulcer in mother's case history were also in this stratum. As regards the effect (AG), there were only 2 AG cases in S1 stratum (the fraction amounted to 0.053 ; Table 3 ). All the rest 47 individuals had normally functioning stomach in $11 \%$ cases; in $89 \%$ cases they suffered from non-atrophic helicobacter gastritis.

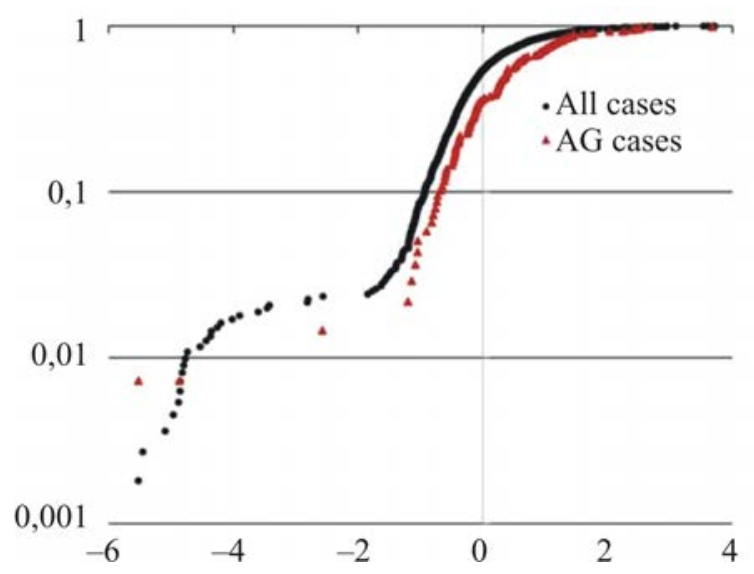

Figure 1. Empiric cumulative distributions of all cases and AG cases in the sampling as per projection value of aggregated factor burden along the major trend 
Table 2

Distribution of cases as per strata along the major trend in factors changeability (as regards categorical factors)

\begin{tabular}{|c|c|c|c|c|c|c|c|c|c|c|}
\hline Strata & S1 $(0-4.8)$ & \multicolumn{2}{|c|}{ S2 $(4.8-6.2)$} & \multicolumn{2}{c|}{ S3 $(6.2-8.1)$} & \multicolumn{2}{l|}{ S4 (8.1-9.77) } & \multirow{2}{*}{$n / N$} & \multirow{2}{*}{$P$-value } \\
\hline Factors & Yes & No & Yes & No & Yes & No & Yes & No & & $\approx 0$ \\
\hline $2(\mathrm{f}=1)$ & 19 & 30 & 208 & 422 & 236 & 162 & 28 & 11 & $4 / 6$ & $\approx 0.0017$ \\
\hline $3^{\dagger}$ & 38 & 11 & 499 & 131 & 276 & 122 & 22 & 17 & $2 / 6$ & 0.000 \\
\hline $4^{\dagger}$ & 26 & 23 & 277 & 353 & 46 & 352 & 1 & 38 & $4 / 6$ & $\approx 0$ \\
\hline $5^{\dagger}$ & 5 & 44 & 66 & 564 & 174 & 224 & 15 & 24 & $4 / 6$ & $\approx 0$ \\
\hline $8^{\dagger}$ & 16 & 33 & 204 & 426 & 82 & 316 & 5 & 34 & $2 / 6$ & $<0.0001$ \\
\hline 9 & 7 & 42 & 112 & 518 & 49 & 349 & 4 & 35 & $0 / 6$ & $\mathbf{0 . 0 8 5}$ \\
\hline $10^{\dagger}$ & 20 & 29 & 244 & 386 & 100 & 298 & 8 & 31 & $1 / 6$ & $<0.0001$ \\
\hline 11 & 10 & 39 & 144 & 486 & 55 & 343 & 4 & 35 & $1 / 6$ & 0.0018 \\
\hline 12 & 19 & 30 & 277 & 353 & 105 & 293 & 8 & 31 & $2 / 6$ & $<0.0001$ \\
\hline 13 & 12 & 37 & 201 & 429 & 77 & 321 & 6 & 33 & $1 / 6$ & $<0.0001$ \\
\hline $14^{*}$ & 0 & 49 & 4 & 626 & 7 & 391 & 13 & 26 & $3 / 6$ & $\approx 0$ \\
\hline $15^{*}$ & 0 & 49 & 11 & 619 & 15 & 383 & 7 & 32 & $3 / 6$ & $<0.0001$ \\
\hline 16 & 1 & 48 & 0 & 630 & 35 & 363 & 37 & 2 & $4 / 6$ & $\approx 0$ \\
\hline $17^{\dagger}$ & 3 & 46 & 39 & 591 & 13 & 385 & 1 & 38 & $0 / 6$ & $\mathbf{0 . 1 7}$ \\
\hline 18 & 3 & 46 & 19 & 611 & 41 & 357 & 6 & 33 & $2 / 6$ & $<0.0001$ \\
\hline 19 & 0 & 49 & 35 & 595 & 52 & 346 & 2 & 37 & $2 / 6$ & $<0.0001$ \\
\hline 20 & 24 & 25 & 187 & 443 & 48 & 350 & 2 & 37 & $5 / 6$ & $\approx 0$ \\
\hline 21 & 9 & 40 & 25 & 605 & 164 & 234 & 25 & 14 & $6 / 6$ & $\approx 0$ \\
\hline $22^{*}$ & 0 & 49 & 21 & 609 & 15 & 383 & 5 & 34 & $1 / 6$ & 0.01 \\
\hline $23^{*}$ & 1 & 48 & 35 & 595 & 35 & 363 & 9 & 30 & $2 / 6$ & 0.00012 \\
\hline $24^{\dagger}$ & 26 & 23 & 0 & 630 & 0 & 398 & 0 & 39 & $3 / 6$ & $\approx 0$ \\
\hline 25 & 2 & 47 & 60 & 570 & 25 & 373 & 0 & 39 & $1 / 6$ & 0.043 \\
\hline $\begin{array}{c}\text { Effect } \\
\text { (AG) }\end{array}$ & 2 & 47 & 50 & 580 & 76 & 322 & 9 & 30 & $4 / 6$ & $\approx 0$ \\
\hline
\end{tabular}

Note:

$1-P$-value according to Pearson within zero hypothesis $H O$ on prevalence of each factor or effect (table $4 \times 2$ for each line);

$2-n / N$ is a number of statistically significantly different pairs of strata $\mathrm{n}$ out of $N$ possible (Bonferroni corrections taken into account);

$3 P$-value of statistically insignificant factors are given in semibold type;

* means a trend in factor prevalence as per strata is similar to an effect trend

${ }^{\dagger}$ means a trend in factor prevalence as per strata contradicts to an effect trend

Table 3

AG prevalence (in fractions) in different strata/clusters

\begin{tabular}{|c|c|c|c|c|c|}
\hline \multicolumn{2}{|c|}{ Groups } & Number of people & AG cases & $\begin{array}{l}\text { AG prevalence, median } \\
{[90 \% \text { confidence interval }}\end{array}$ & P-value \\
\hline \multirow{4}{*}{ Strata } & S1 & 49 & 2 & $0.053(0.017-0.121)$ & \multirow{4}{*}{$\mathrm{P}<10^{-6}$} \\
\hline & $\mathrm{S} 2$ & 630 & 50 & $0.080(0.064-0.099)$ & \\
\hline & S3 & 398 & 76 & $0.192(0.161-0.226)$ & \\
\hline & $\mathrm{S} 4$ & 39 & 9 & $0.240(0.142-0.360)$ & \\
\hline \multirow{3}{*}{ Clusters } & S5 & 26 & 2 & $0.098(0.031-0.215)$ & \multirow{3}{*}{$\mathrm{P}=0.46$} \\
\hline & S6 & 1,001 & 121 & $0.121(0.105-0.139)$ & \\
\hline & S7 & 89 & 14 & $0.162(0.106-0.232)$ & \\
\hline
\end{tabular}




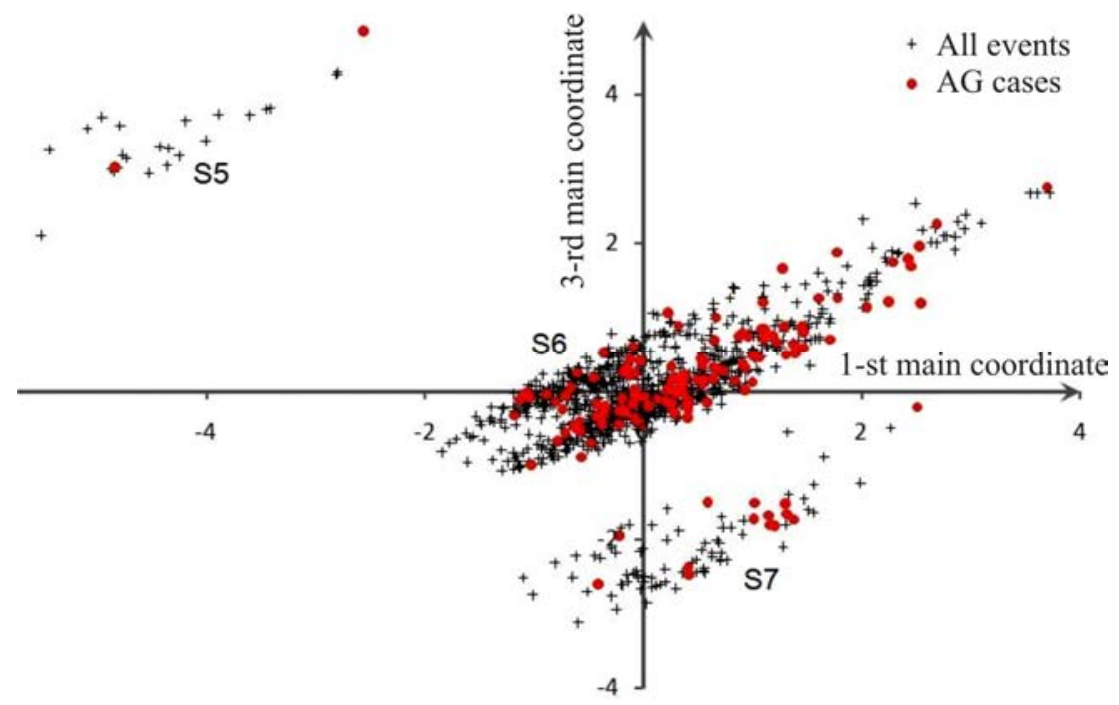

Figure 2. Distribution of events without AG (crosses) and AG cases (rounds) within the plane of two centered principal components in the factor space

S4 stratum was completely opposite to S1 stratum as per a number of predisposing factors and their prevalence. It contained the highest share of women and elderly people; it had high fractions of people who contacted adverse chemicals, people with SC in case histories of family members, people with AID (predominantly autoimmune thyroiditis), with hormone-dependent benign tumors and precancer diseases, with MN not located in the stomach, and with non-ulcer gastric diseases. But still the fraction of smoking people was the lowest in this stratum; there was no stomach ulcer in case histories of parents, and the stratum also had the lowest prevalence of gastric acid-dependent diseases. It should be noted that the highest AG share was detected exactly in S4 stratum (0.24). Strata S2 and S3 had various transient states; AG prevalence in stratum S2 (0.08) was close to that in $\mathrm{S} 1$, and in stratum S3 (0.19), to that in S4 (Table 3).

Obviously, it is interesting to perform analysis not only as per one principal component, but also as per other ones. Thus, when we added other centered orthogonal components into distributions of all cases, it allowed us to reveal three well-defined clusters that could indicate there was possibly a cause-andeffect relation between factors (Figure 2). Cluster S5 turned out to be very close to stratum S1 as per a set of factors and obviously it was completely included into this stratum.
All statistical tests that give an opportunity to "work" with zero values in cells of relevant tables identify a combination of these facts as being a non-random one. We can state that all the listed extreme values of signs are linked both to each other and to a comparatively low averaged value of AG prevalence in cluster S5 against clusters S6 and S7 (Table 3). Cluster S7 also has a common sign, namely, all the cases with pancreatic diabetes are located in it. Independent grouping performed for S7 cluster indicates that there is a link to other signs but it is not as obvious as it is the case with cluster S5. We should note that links between certain factors/signs don't necessarily mean a link between them and the effect (AG) is obvious; it is proven by estimates of how statistically significant $A G$ prevalence is in strata S5, S6, and S7 (Table 3). Despite there is a monotonous growth in median AG prevalence from S5 to S7, strata sizes and distribution of specific events in them were not sufficient for Pearson's P-value to surmount conventional decision-making level 0.05 for each of the pairs S5-S6, S6-S7 and S5-S7.

So, basing on the applied procedure that was a substitute to multi-factor analysis, we can only conclude that there are certain trends in risks of $\mathrm{AG}$ occurrence when aggregated factor burden changes. Risk values could be 4-5 times higher or lower between certain subgroups in the examined sampling. For exam- 
ple, relative risk (RR) of $A G$ in strata $\mathrm{S} 4: \mathrm{S} 1$ reached 4.49 (90\% CI: 1.70-15.37). As S1 and S2 strata were heterogeneous, ratios of individual risks could be substantially higher. Nevertheless, we can't neglect a possible multi-factor influence exerted on AG prevalence as such influence is confirmed by statistical criteria calculated for two pairs of noncrossing strata S9-S8 and S11-S10 which were artificially selected as per a combination of several factors.

Factors that could have either positive or negative influence on AG risks were selected according to our own data and those available in literature. It was shown that smoking didn't exert any influence on occurrence of atrophic changes in GM; there was even lower $A G$ prevalence among smoking people $[9,12]$. In our opinion, this peculiar "protection" of gastric mucosa from atrophic changes that occurs due to smoking results from competing interrelations at the regulatory level or genetic dominating for binding places between effects produced by nicotine and humoral factors causing GM atrophy. There are data that autoimmune diseases (especially autoimmune thyroiditis and diabetes mellitus) and gastric pathology are correlated and mutually determined. Over the last decade experts have even applied "thyrogastric syndrome" definition [19]. Indeed, $\mathrm{AG}$ fraction was the lowest in stratum S1 where there were no DM cases while it was the highest in cluster S7 where all the DM cases were located (Table 3 ).

Taking into account all the given data and results of estimating correlations between factors and the effect (Table 2), some strata were made up of people who had factors with their prevailing trend being opposite to $A G$ trend; alternative strata included people with "pro-atrophic" factors. Thus, if stratum S8 was made up of only smoking men who didn't suffer from AID, then S9 stratum included only women who didn't smoke and suffered from an AID. S10 stratum included predominantly men who worked in various non-industrial establishments and didn't have any contacts with adverse chemicals without any AID in their anamnesis. On the contrary, S11 stratum in- cluded predominantly women employed at Mayak PA who were exposed to chemical carcinogens, suffered from gastric acid-dependent diseases and had hereditary predisposition to ulcer (Table 4). AG prevalence in pairs of strata S8-S9 and S10-S11 had significant intergroup discrepancies $(\mathrm{P}<0.001$ according to any existing statistical criteria) (Table 4). Bayesian median estimate of relative risk amounted to 4.38 for S8-S9 pair (90\% CI: $2.75-6.89$ ); and to 11.0 for S11-S10 pair (90 \% CI: 5.22-26.9), and we certainly can't neglect that.

Table 4

AG prevalence (in fractions) in S8-S11 strata

\begin{tabular}{|c|c|c|c|c|}
\hline Strata & $\begin{array}{c}\text { Number } \\
\text { of people }\end{array}$ & $\begin{array}{l}\text { AG } \\
\text { cases }\end{array}$ & $\begin{array}{c}\text { AG prevalence, } \\
\text { median } \\
\text { (90\% CI of } \\
\text { uncertainty) }\end{array}$ & $\begin{array}{c}\mathrm{RR} \\
(90 \% \mathrm{CI})\end{array}$ \\
\hline S8 & 282 & 22 & $\begin{array}{c}0.080 \\
(0.056-0.109)\end{array}$ & \multirow{2}{*}{$\begin{array}{c}4.38 \\
(2.75-6.89)\end{array}$} \\
\hline S9 & 49 & 17 & $\begin{array}{c}0.351 \\
(0.247-0.465)\end{array}$ & \\
\hline S10 & 106 & 4 & $\begin{array}{c}0.043 \\
(0.019-0.083)\end{array}$ & \multirow{2}{*}{$\begin{array}{c}11.0 \\
(5.22-26.9)\end{array}$} \\
\hline S11 & 27 & 13 & $\begin{array}{c}0.482 \\
(0.333-0.634)\end{array}$ & \\
\hline
\end{tabular}

We examined AG prevalence in case people in the sampling were grouped only as per their place of work; this examination revealed that it amounted to $4.8 \%$ among people who were not exposed to technogenic irradiation and harmful chemicals (people working in non-industrial establishments) [12]. It is consistent with a fraction prevalence of the effect observed in strata $\mathrm{S} 1$ and S10 within uncertainty limits $(0.053$ and 0.043 accordingly) (Tables 3 and 4). At the same tine AG prevalence among workers employed at Mayak PA (14.8\%-20\%) [12] corresponded to the results of fraction estimates of the effect in stratum S4 and cluster S7 (0.24-0.16) (Table 3). In our opinion, this coincidence in an increase in $\mathrm{AG}$ prevalence in industrial workers sub-group and in created stratum S4 and cluster S7 confirms that workers employed at nuclear production are more quantitatively "burdened" with factors that predispose AG occurrence as well as that there are qualitatively other factors that cause higher AG prevalence among them. 
We should note that our exploratory analysis didn't allow us to reduce a list of factors that could potentially influence risks of AG occurrence. Basing on factors distribution as per different strata, we can conclude that only two factors, namely F9 and F17, didn't exert any statistically significant influence on AG occurrence within the limits of our examined sampling (Table 2). "Pro-atrophic" effects are most likely to be produced by such factors as age (F1), external irradiation dose (F6), pre-cancer diseases (F14), MN not located in the stomach (F15), hormonedependent benign tumors (F16), non-ulcer gastric diseases (F21), and hereditary predisposition to stomach cancer (F22-23). The first major trend has a single vector with projections having such value and sign that it allows us to assume changes in these factors occurring in consistency with an increase in risks of AG. At the same time such factors as alcohol intake (F3), smoking (F4), acid-dependent gastric diseases in case history (F20), ulcer in mother's case history (F24), and concentration of antibodies to H. pylori (F26) had a direction that was opposite to risks of AG occurrence. For these factors, AG risks trend was also opposite even as per a sign of a factor prevalence trend. Such an opposite direction detected for impacts exerted by certain organic chemicals (F8, F10) is not consistent with conventional opinion on adverse effects produced by them; the issue requires further investigation. Probably a distribution of factors which we obtained doesn't give us a correct picture due to cases being grouped arbitrarily or mutual correlations between factors when impacts exerted by one factors were somehow disguised by those exerted by another.

It came out that both procedures which we applied (graphs and tables) didn't allow giving a complete picture due to probable correlations between factors and even their mutual dependence. Another circumstance that makes any analysis even more difficult is an a priori assumption that factors make equal contributions into the overall "burden"; it means an issue related to mathematic standardizing of $\mathrm{R}^{26}$ space is not properly regulated. However, individual data on factors occurrence in each stratum allowed making direct comparisons between AG prevalence in strata with heterogeneous distribution of factors. Besides, basing on our pilot research, we can assume that observed prevalence of atrophic gastritis in the examined sampling can't correspond to a typical zero hypothesis $H O$ that there is no correlation between the effect and factors. Given that, we should take another basic hypothesis for making any probabilistic estimates; this alternative hypothesis $H 1$ states there is a correlation between the effect and almost all the examined factors. It is advisable to perform relevant estimates with maximum-likelihood techniques applying a distribution that is typical for en empirical sampling itself, and considering alternatives to $H 1$ comparing them with it. It necessarily leads us to Wilkes or Kullback tests [20]. Obviously, full-fledged statistical analysis should be only multi-factor one. Nature of "factor - effects" relations is usually intricate and not obvious, and it gives opportunities for artificial neural networks approximations. We are planning to dwell on it in our future works.

Funding. The research was not granted any financial support.

Conflict of interests. The authors declare there is no any conflict of interests.

\section{References}

1. Torre L.A., Bray F., Siegel R.L., Ferlay J., Lortet-Tieulent J., Jemal A. Global cancer statistics, 2012. CA Cancer J. Clin, 2015, vol. 65, no. 2, pp. 87-108. DOI: $10.3322 /$ caac. 21262

2. Zlokachestvennye novoobrazovaniya v Rossii v 2016 g. (zabolevaemost', smertnost') [Malignant neoplasms in Russia in 2016 (morbidity and mortality)]. In: A.D. Kaprin, V.V. Starinskii, G.V. Petrova eds. Moscow, MNIOI im. P.A. Gertsena - filial FGBU "NMIRTs" Minzdrava Rossii Publ., 2018, 250 p. (in Russian).

3. Correa P. Human gastric carcinogenesis: a multistep and multifactorial process. FACSAL on CEP. Cancer Res, 1992, vol. 52, pp. 6735-6742.

4. Vannella L., Lahner E., Annibale B. Risk for gastric neoplasias in patients with chronic atrophic gastritis: A critical reappraisal. World J. Gastroenterol, 2012, vol. 18, no. 12, pp. 1279-1285. DOI: 10.3748/wjg.v18.i12.1279 
5. Song H., Ekheden I.G., Zheng Z., Ericsson J., Nyrén O., Ye W. Incidence of gastric cancer among patients with gastric precancerous lesions: observational cohort study in a low risk Western population. Br. Med. J, 2015, vol. 27, no. 351, pp. 3867. DOI: 10.1136/bmj.h3867

6. Khomyakov V.M., Ermoshina A.D., Pirogov S.S., Ryabov A.B. Stomach cancer risk factors: the modern concept. Rossiiskii zhurnal gastroenterologii, gepatologii, koloproktologii, 2017, vol. 27, no. 6, pp. 78-86 (in Russian).

7. Muszyński J., Biernacka D., Siemińska J., Górnicka B., Bogdańska M. Effect of age and sex on the occurrence of gastritis changes in gastric mucosa. Pol. Arch. Med. Wewn, 1996, vol. 95, no. 6, pp. 542-548.

8. Risk factors for atrophic chronic gastritis in a European population: results of the Eurohepygast study. The Eurohepygast Study Group. Gut, 2002, vol. 50, no. 6, pp. 779-785. DOI: 10.1136/gut.50.6.779

9. Hishida A., Matsuo K., Goto Y., Naito M., Wakai K., Tajima K., Hamajima N. Smoking behavior and risk Helicobacter pylori infection, gastric atrophy and gastric cancer in Japanese. Asian. Pac. J. Cancer Prev, 2010, vol. 11, no. 2, pp. 313-317.

10. Osipov M.V., Sokol'nikov M.E. Assessment of Mortality Risk from Malignant Neoplasms Developed in Gastrointestinal Organs in Mayak PA Workers. Voprosy radiatsionnoi bezopasnosti, 2014, no. 1 (73), pp. 76-83 (in Russian).

11. Rabinovich E.I., Obesnyuk V.F., Povolotskaya S.V., Sokolova S.N., Turdakova V.A. Impact Assessment of Carcinogenic Factors on the Atrophic Gastritis in the Cohort of Workers of the Nuclear Facility. Meditsinskaya radiologiya i radiatsionnaya bezopasnost', 2015, vol. 60, no. 5, pp. 31-39 (in Russian).

12. Solov'ev V.Yu., Bushmanov A.Yu., Semenov V.G., Kochetkov O.A., Torubarov F.S. The Conceptual Approach to Identification of Risk Groups among Atomic Industry Workers. Meditsinskaya radiologiya i radiatsionnaya bezopasnost', vol. 54, no. 6, pp. 16-23 (in Russian).

13. Kurilovich S., Belkovets A., Reshetnikov O., Openko T., Malyutina S., Ragino Y., Scherbakova L., Leja M. [et al.]. Stomach specific Biomarkers (Gastro Panel) Can Predict the Development of Gastric Cancer in a Caucasian Population: A Longitudinal Nested Case-Control Study in Siberia. Anticancer Res, 2016, vol. 36, no. 1, pp. 247-253.

14. Jolliffe I.T. Principal Component Analysis. Springer Series in Statistics. 2nd edition. NewYork, Springer Publ., 2002, 487 p.

15. Altham P. Exact Bayesian analysis of $2 \times 2$ contingency table and Fisher's exact significance test. Journal of the Royal Statistical Society. Series B, 1969, vol. 31, no. 2, pp. 261-269. DOI: 10.1111/j.2517-6161.1969.tb00786.x

16. Obesnyuk V.F., Khromov-Borisov N.N. Interval'nye otsenki pokazatelei sravnitel'nogo medikobiologicheskogo issledovaniya [Interval estimates for parameters of a comparative medical and biological examination]. Aktual'nye Problemy Sovremennoi Nauki: Mezhvuzovskii sbornik nauchnykh trudov s materialami 10-i mezhdunarodnoi telekonferentsii, 2013, vol. 2, no. 1, pp. 154-156 (in Russian).

17. Rapoport S.I. Gastrity. Posobie dlya vrachei [Gastritis. A manual for physicians]. Moscow, Medpraktika Publ., 2010, 19 p. (in Russian).

18. Sterzl I., Hrda P., Matucha P., Cerovská J., Zamrazil V. Anti-Helicobacter pylori, AntiThyroid Peroxidase, Anti-Thyroglobulin and Anti-Gastric Parietal Cells Antibodies in Czech Population. Physiol. Res, 2008, vol. 57, no. 1, pp. 135-141.

19. Kullback S., Kupperman M., Ku H.H. An application of information theory to the analysis of contingency tables. Journal of Research of the National Bureau of Standards, 1962, vol. 66B, no. 4, pp. 217-243.

20. Wilks S.S. The large sample distribution of the likelihood ratio for testing composite hypotheses. The Annals of Mathematical Statistics, 1938, vol. 9, no. 1, pp. 60-62. DOI: 10.1214/aoms/1177732360

Rabinovich E.I., Obesnyuk V.F., Povolotskaya S.V., Sokolova S.N., Vasina M.A., Sokol'nikova S.S. Relation between atrophic gastritis and risk factors prevalence among workers employed at atomic enterprise. Health Risk Analysis, 2019, no. 4, pp. 104-112. DOI: 10.21668/health.risk/2019.4.11.eng

Received: 25.04 .2019

Accepted: 27.11 .2019

Published: 30.12 .2019 